\title{
Structural and magnetic properties of $\mathrm{Ni}_{0.5} \mathrm{Zn}_{0.5} \mathrm{Sm}_{\mathrm{x}} \mathrm{Fe}_{2-\mathrm{x}} \mathrm{O}_{4}$ nanoferrite by sol-gel auto-combustion method
}

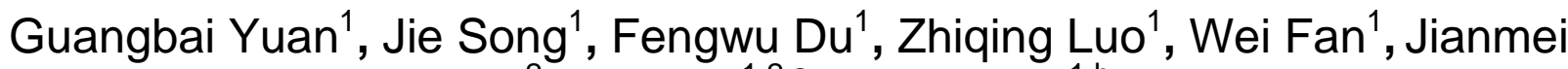 \\ $\mathrm{Xu}^{2}$, Qing Lin ${ }^{1,2, a}$ and Yun $\mathrm{He}^{1, \mathrm{~b}}$ \\ ${ }^{1}$ College of Physics and Technology, Guangxi Normal University, Guilin 541004, China \\ ${ }^{2}$ College of Medical Informatics, Hainan Medical University, Haikou 571199, China
}

Keywords: Structural and magnetic properties,sol-gel auto-combustion method, $\mathrm{Ni}_{0.5} \mathrm{Zn}_{0.5} \mathrm{Sm}_{\mathrm{x}} \mathrm{Fe}_{2-}$ ${ }_{\mathrm{x}} \mathrm{O}_{4}$ nanoferrite

Abstract. Samarium ion substituted magnesium of $\mathrm{Ni}_{0.5} \mathrm{Zn}_{0.5} \mathrm{Sm}_{\mathrm{x}} \mathrm{Fe}_{2-\mathrm{x}} \mathrm{O}_{4}$ spinel ferrite powders have been prepared by a sol-gel auto-combustion method. XRD results indicate that the production of a single cubic phase of ferrites. Some particles are agglomerated due to the presence of magnetic interactions among particles. The Mössbauer spectra of $\mathrm{Ni}_{0.5} \mathrm{Zn}_{0.5} \mathrm{Sm}_{\mathrm{x}} \mathrm{Fe}_{2-\mathrm{x}} \mathrm{O}_{4}$ nanocrystalline at room temperature show that the magnetic interaction and interface atomic state were influenced strongly by $\mathrm{Sm}^{3+}$ ratio, and the saturation magnetization of a spinel ferrite largely also depends on $\mathrm{Sm}^{3+}$ ratio and particle size, while the coercive field depends on $\mathrm{Sm}^{3+}$ ratio, particle size and their shapes. The SEM micrographs indicate that the Nanocrystalline Particles' specific features and characteristics.

\section{Introduction}

$\mathrm{Ni}-\mathrm{Zn}$ ferrite ceramic is a kind of spinel-structured material with good magnetism. The magnetic properties of the ferrite are highly sensitive to the amount of constituent metal oxides in their compositions, and rare earth oxides are becoming promising additives to improve the magnetic properties of ferrites.Recently, Many people in order to modify microstructure and magnetic properties of the spinel structure ferrites, the substitution of small amount of rare earth(RE) ions for ferrites has been attracted more attentions ${ }^{[1-4]}$.In this context, purpose of the work is too detailed discussion structural and magnetic properties of $\mathrm{Ni}_{0.5} \mathrm{Zn}_{0.5} \mathrm{Sm}_{\mathrm{x}} \mathrm{Fe}_{2-\mathrm{x}} \mathrm{O}_{4}$ ferrites . Among the several rare earth ions studied in the literature, samarium, specifically, has resulted in quite significant values of the magnetic properties of the Ni-Zn ferrite. The microstructural and magnetic properties of resulting nanoparticles were investigated by XRD,TEM and Mössbauer measurements.

\section{Experimental}

\section{Sample preparation}

The raw materials utilized in the present study were analytical grade nickel nitrate $\left[\mathrm{Ni}\left(\mathrm{NO}_{3}\right)_{2} \cdot 6 \mathrm{H}_{2} \mathrm{O}\right]$, zinc nitrate $\left[\mathrm{Zn}\left(\mathrm{NO}_{3}\right)_{2} \cdot 6 \mathrm{H}_{2} \mathrm{O}\right]$, iron nitrate $\left[\mathrm{Fe}\left(\mathrm{NO}_{3}\right)_{3} \cdot 9 \mathrm{H}_{2} \mathrm{O}\right]$, samarium nitrate $\left[\mathrm{Sm}\left(\mathrm{NO}_{3}\right)_{3} \cdot 6 \mathrm{H}_{2} \mathrm{O}\right]$ and citric acid $\left[\mathrm{C}_{6} \mathrm{H}_{8} \mathrm{O}_{7} \cdot \mathrm{H}_{2} \mathrm{O}\right]$ were used to prepare stoichiometric $\mathrm{Ni}_{0.5} \mathrm{Zn}_{0.5} \mathrm{Sm}_{\mathrm{x}} \mathrm{Fe}_{2-\mathrm{x}} \mathrm{O}_{4}(\mathrm{x}=0 、 0.05 、 0.1 、 0.15$ and 0.2$)$ by sol-gel auto-combustion method. These were dissolved in a mixed solvent system ( metal nitrates and citric acid were dissolved in deionized water and were mixed in 1:1 molar ratio). Then the PH of the solution was adjusted to about 7-8 using ammonia solution. The next solution was heated at $80^{\circ} \mathrm{C}$ until transformed into gel and the wet gel was dried in digital display drying cabinet at $120^{\circ} \mathrm{C} / 2 \mathrm{~h}$. When the dried gel was ignited with peroxide anhydrous ethyl alcohol, the auto-combustion rapidly propagated forward until all the gel burnt completely and form dark brown loose powder. Lastly, the as-burnt precursors were sintered in muffle furnace at $900^{\circ} \mathrm{C} / 3 \mathrm{~h}$.

\section{Characterizations}

The thermal decomposition behavior of gel was analyzed by thermal analysis instrument (SDT Q600, America). The crystalline structure of sample was performed using X-ray diffraction (D8 Advance, Germany) with $\mathrm{Cu} K \alpha$ radiation $(\lambda=0.15405 \mathrm{~nm})$. The microstructure of particles was observed by scanning electron microscope (SU8020, Japan). The hysteresis loop of sample was 
measured by Superconducting Quantum Interference Device (MPMS-XL-7, America) at room temperature. The Mössbauer spectra were performed using conventional Mössbauer spectrometer (Fast Com Tec PC-mossII) at room temperature, in constant acceleration modeat. The $\gamma$-ray was provided by a ${ }^{57} \mathrm{Co}$ source in a rhodium matrix.

\section{Results and discussion}

\section{XRD analysis}

Figure 1 shows the room-temperature $x$-ray diffraction pattern of the $\mathrm{Ni}_{0.5} \mathrm{Zn}_{0.5} \mathrm{Sm}_{\mathrm{x}} \mathrm{Fe}_{2-\mathrm{x}} \mathrm{O}_{4}$ analyzed by jade 5 software. All samples were sintered at $900^{\circ} \mathrm{C}$ and cooling at room temperature in the air. Comparison of international standard card phase, from the characteristic diffraction peaks $(220,311,222,400,422,511,440)$, we can see seven samples were cubic spinel structure. At $\mathrm{x}=0$, that is undoped, there is a small miscellaneous peak, and contrasts $\operatorname{JCPDF}^{[5-8]}$ (33-0664), finds the impurity phase of $\mathrm{Fe}_{2} \mathrm{O}_{3}$, analyzes the causes of impurity phase, probably when configuring the solution, the unreacted part of the iron nitrate, oxide directly situation exists; another explanation is that when sintered at a high temperature of trivalent iron ion directly reacts with the oxygen, generated $\mathrm{Fe}_{2} \mathrm{O}_{3}$. In contrast with the whole samarium doped rare earth elements, the five samples we get are relatively pure, there is not much impurity generation. From this figure, it is easy to see that when samarium ${ }^{[9-12]}$ is very low doping $(x<0.05)$, the samples are mainly spinel ferrite. When $\mathrm{x}$ $=0.1$, the phase appears in the second doping ${ }^{[13-15]} \mathrm{SmFeO}_{3}$, particularly with the increase in the amount of doping, when $\mathrm{x}=0.2$, the diffraction peak of the impurity phase is particularly evident.To better illustrate the movement of the characteristic peaks' angle, we did a simple processing.

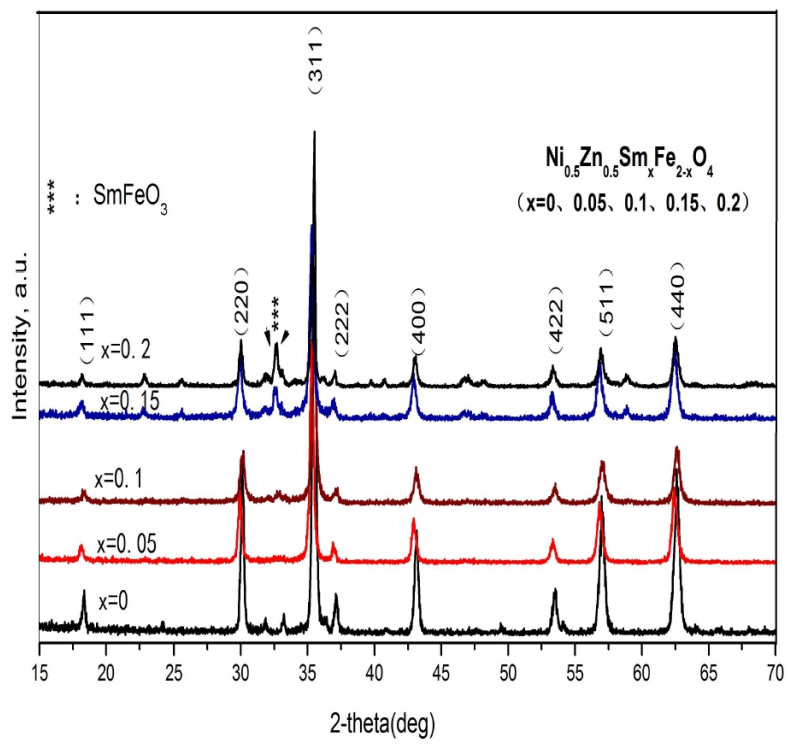

Figure 1. XRD patterns of samples calcined at $900^{\circ} \mathrm{Cwith}$ the different Sm-doped

In the Figure 2 ,All of the characteristic peaks(311) had significant movement, we get results from the figure and theoretical analysis is consistent. Furthermore, we also proved successful doping.Table 1 shows the diffraction peak width and the average grain size. The average grain size of $\mathrm{Ni}_{0.5} \mathrm{Zn}_{0.5} \mathrm{SmxFe}_{2-\mathrm{x}} \mathrm{O}_{4}$ ferrites what about samarium ions molar, when the low doping ( $\left.<<0.1\right)$, the average grain size increases as the amount of samarium ions. The reasons explained as follows, because the $\mathrm{B}$ bit in the trivalent iron ions are substituted with an ionic radius more larger trivalent samarium ion, leading to distortion of the lattice distortion, so that the grain of the barrier rises, the lattice strain and stress increase large, hindering grain growth. Also noteworthy, the sample ions of rare earth samarium undoped average grain size is larger than the relative doped samples; reflected from the side, and the Sm ions grain refinement effect, be prepared to provide an idea that the particle size is small crystals. 


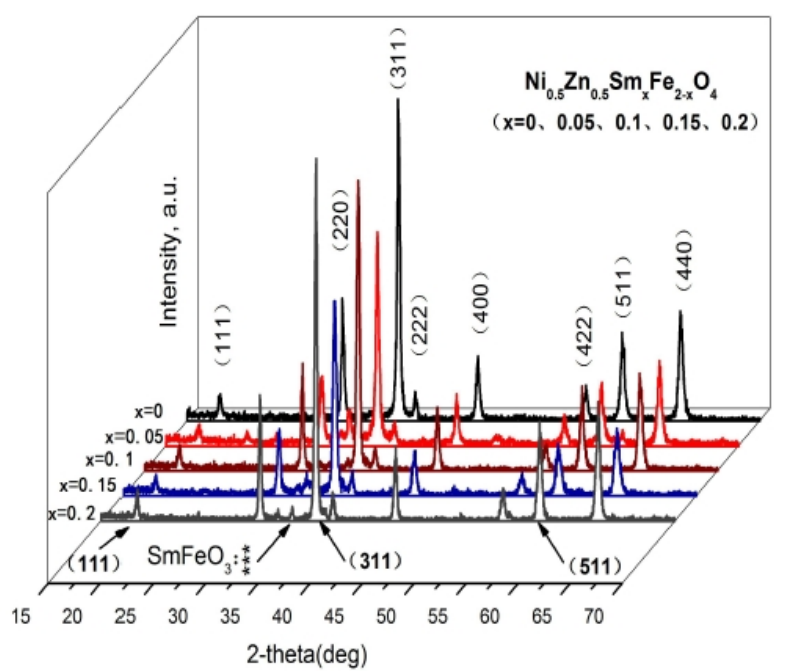

Figure 2. XRD patterns of samples' Three-dimensional map

When a higher doping amount $(x>0.1)$, it can be seen, the average grain size becomes large. This is because a large ionic radius samarium replace a relatively small iron ions, excess doping, will lead to lattice expansion, so crystal lattice parameter increases. In addition, we know from the diffraction pattern, excess samarium, forming a hybrid phase $\left(\mathrm{SmFeO}_{3}\right)$, the lattice parameter becomes larger, but $\mathrm{SmFeO}_{3}$ formed simultaneously form a complete, isolated thin film, stay at the grain boundaries, resulting in the internal stress, resulting in distortion of the lattice, the lattice parameter decreases, but the degree of decrease of the overall hybrid is not formed with the lattice parameter becomes large to a large extent. By contrast doped and undoped samples, the average grain size is relatively reduced, once again proved: the role of rare earth samarium ion grain refinement.

Table 1. The XRD parameters for samples with doping Sm calcined at $900^{\circ} \mathrm{C}$

\begin{tabular}{cccc}
\hline $\begin{array}{c}\text { Sampl } \\
\mathrm{e}(\mathrm{x})\end{array}$ & $\begin{array}{c}\text { Average } \\
\text { crystallit } \\
\text { e size }\end{array}$ & $\begin{array}{c}\text { Lattice } \\
\text { parameter } \\
(\AA)\end{array}$ & $\begin{array}{c}\text { Densit } \\
\mathrm{y} \\
\left(\mathrm{g} \cdot \mathrm{cm}^{-}\right.\end{array}$ \\
\hline 0 & 36.5 & 8.433 & 5.339 \\
\hline 0.05 & 29.2 & 8.433 & 5.339 \\
\hline 0.1 & 24.1 & 8.383 & 5.361 \\
\hline 0.15 & 25.3 & 8.433 & 5.339 \\
\hline 0.2 & 29.5 & 8.433 & 5.339 \\
\hline \hline
\end{tabular}

\section{Magnetic property}

Figure 3 shows the magnetic property of $\mathrm{Ni}_{0.5} \mathrm{Zn}_{0.5} \mathrm{Sm}_{\mathrm{x}} \mathrm{Fe}_{2-\mathrm{x}} \mathrm{O}_{4}(\mathrm{x}=0.05 、 0.1 、 0.15$ and 0.2$)$ annealed at $900^{\circ} \mathrm{C}$, cooled to room temperature magnetic hysteresis curves, Which figure among the small figure shows the coercivity changes.The saturation magnetization of the samples with increasing molar amounts of samarium ions, and decreases linearly, remanence and coercivity did not change significantly; however, in contrast to the doping and the undoped sample, the sample coercive force is slightly larger than the undoped doped samples, but rather a change in the remanence of more regular; Further, we can see the maximum energy of the sample variation of the area, but also does not have a significant variation.Analysis and discussion, we can see several reasons for the impact of the magnetic properties of the sample changes: the introduction of rare earth elements samarium, re-distribution of various ions in the crystal lattice arrangement; impurity phase $\mathrm{SmFeO}_{3}, \mathrm{Fe}_{2} \mathrm{O}_{3}$ generation, the internal stress generated at the grain boundaries; for these reasons, the magnetic domain structure becomes complicated, and many other reasons dramatically affect the magnetic properties of the samples ${ }^{[16-17]}$. 


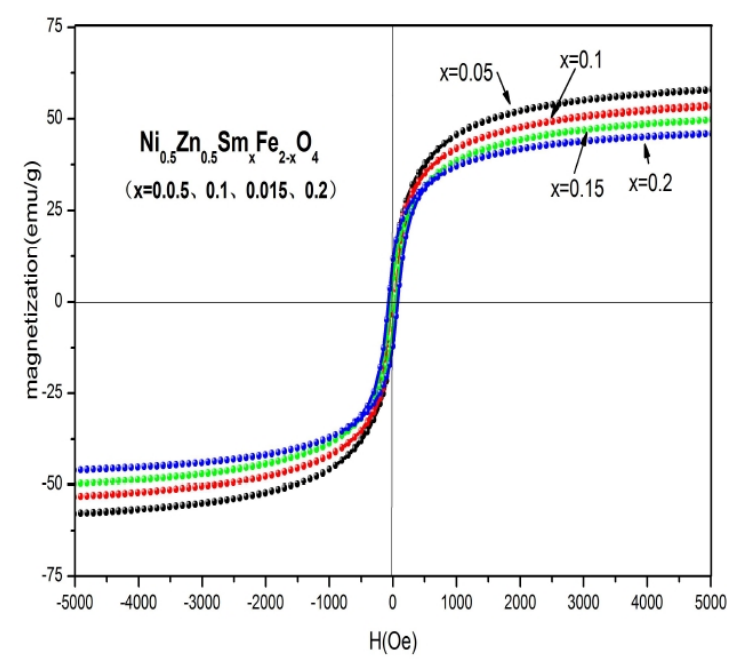

Figure 3. Hysteresis of $\mathrm{Ni}_{0.5} \mathrm{Zn}_{0.5} \mathrm{Sm}_{\mathrm{x}} \mathrm{Fe}_{2-\mathrm{x}} \mathrm{O}_{4}$

Mössbauer spectrum analysis

The Mössbauer spectra of $\mathrm{Ni}_{0.5} \mathrm{Zn}_{0.5} \mathrm{Fe}_{2} \mathrm{O}_{4}$ and $\mathrm{Ni}_{0.5} \mathrm{Zn}_{0.5} \mathrm{Sm}_{\mathrm{x}} \mathrm{Fe}_{2-\mathrm{x}} \mathrm{O}_{4} \quad(\mathrm{x}=0 、 0.05 、 0.1 、 0.15$ and 0.2 ) polycrystalline ferrite powders measured at room temperatures (RT) are shown in Figure 4 and Figure 5, respectively.

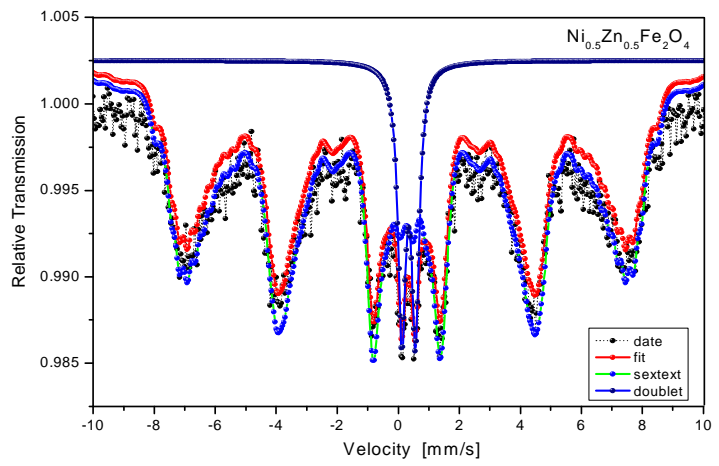

Figure 4. Mössbauer spectra of $\mathrm{Ni}_{0.5} \mathrm{Zn}_{0.5} \mathrm{Fe}_{2} \mathrm{O}_{4}$ ferrite

As can be seen from the figure 4, with six lines and a center lane paramagnetic spectral distribution of the magnetic field, which is confirmed by the spinel phase. We selected $\mathrm{Ni}_{0.5} \mathrm{Zn}_{0.5} \mathrm{Fe}_{2} \mathrm{O}_{4}$ ferrite is derived relaxation phenomenon occurred in the measurement of the Mössbauer results, so in the rare earth-doped samarium later, the entire process of measuring and fitting series of samples are relatively cumbersome. When doping can be very low ( $x<0.1)$, which are relatively simple fitting Mössbauer spectroscopy; When high doping, the Mössbauer fitting relatively complex. Table 2 shows the Mössbauer (RT) parameters of $\mathrm{Ni}_{0.5} \mathrm{Zn}_{0.5} \mathrm{Sm}_{\mathrm{x}} \mathrm{Fe}_{2-}$ ${ }_{\mathrm{x}} \mathrm{O}_{4}$.Mössbauer line width $(\Gamma)$, the relative absorption area parameter values, we can infer that, such distribution among the nickel lattice ions, zinc ions, iron ions, and samarium ions. When the doping molar ratio $\mathrm{x}=0.2$, the isomer shift of undoped samples can vary greatly shift changes. This is because an excess of rare-earth doped samarium, has affected the bond lattice of iron ions and oxygen ions between the distance, leading to an increase of electron cloud overlap of iron ions and oxygen ions $\mathrm{S}$ orbit, so the isomer shift value becomes larger. 


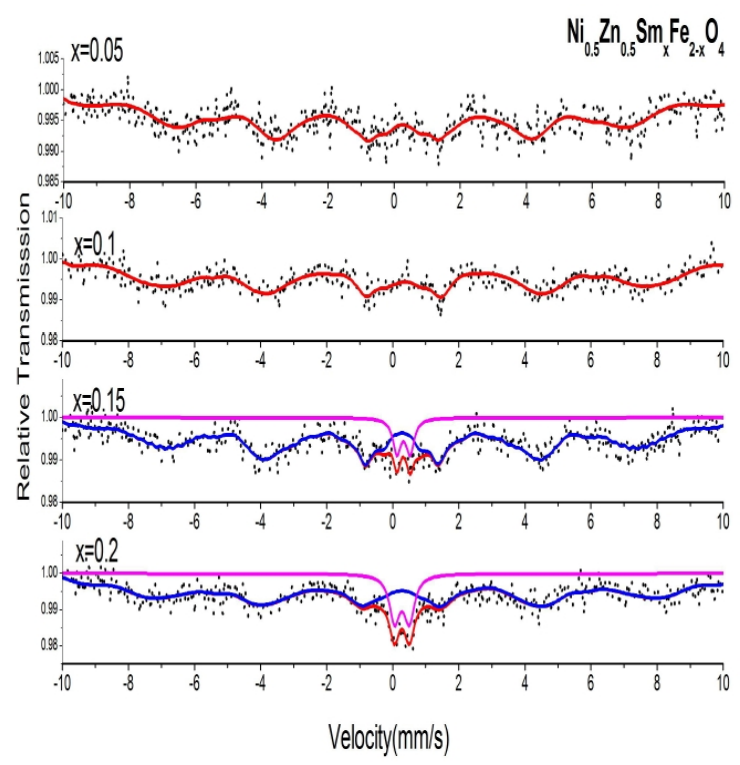

Figure 5. Mössbauer spectra at room temperatures for $\mathrm{Ni}_{0.5} \mathrm{Zn}_{0.5} \mathrm{Sm}_{\mathrm{x}} \mathrm{Fe}_{2-\mathrm{x}} \mathrm{O}_{4} \quad(\mathrm{x}=0.05 、 0.1$ 、 0.15 and 0.2 ) ferrite

Table 2. The Mössbauer spectra of $\mathrm{Ni}_{0.5} \mathrm{Zn}_{0.5} \mathrm{Sm}_{\mathrm{x}} \mathrm{Fe}_{2-\mathrm{x}} \mathrm{O}_{4}$

\begin{tabular}{ccccc}
\hline \multirow{2}{*}{$\begin{array}{c}\text { Sample } \\
(\mathrm{x})\end{array}$} & $\begin{array}{c}\mathrm{IS} \\
(\mathrm{mm} / \mathrm{s})\end{array}$ & $\begin{array}{c}\mathrm{QS} \\
(\mathrm{mm} / \mathrm{s}\end{array}$ & $\begin{array}{c}\Gamma \\
(\mathrm{mm} / \mathrm{s}\end{array}$ & $\begin{array}{c}\mathrm{A}_{0} \\
(\%)\end{array}$ \\
\hline 0 & 0.281 & -0.020 & 0.361 & 95.1 \\
\cline { 2 - 5 } & 0.342 & 0.446 & 0.303 & 4.9 \\
\hline 0.05 & 0.353 & -0.039 & 0.782 & 100 \\
\hline 0.1 & 0.255 & -0.054 & 0.561 & 100 \\
\hline \multirow{2}{*}{0.15} & 0.269 & -0.018 & 0.546 & 95.5 \\
\cline { 2 - 5 } & 0.250 & 1.375 & 0.450 & 4.5 \\
\hline 0.2 & 0.356 & 0.044 & 0.473 & 100 \\
\hline
\end{tabular}

When $\mathrm{x}=0.2$, the isomer shift have the minimum and maximum values, respectively. Indicates the case of trivalent iron ions surrounding environment charge, a relatively stable symmetric charge distribution tends to be a deviation from the comparison, the relative complexity of the charge distribution. As can be seen from the valuesof the hyperfine structure, in contrast to the undoped sample, all the sample values are greater than the doping of undoped samples, This suggests that may be doped with rare-earth ions samarium many samples have nuclear quadrupole moment, nuclear quadrupole moment, they extranuclear electric field gradient produced in nuclear interactions premises, causing small changes in energy, superimposed on hyperfine structure due to the magnetic moment, so that energy splitting deviation interval given the Landes.Because of this, the resulting hyperfine levels hyperfine structure of spectral lines.

\section{SEM analysis}

Figure 6 gives the electron micrograph of $\mathrm{Ni}_{0.5} \mathrm{Zn}_{0.5} \mathrm{Sm}_{\mathrm{x}} \mathrm{Fe}_{2-\mathrm{x}} \mathrm{O}_{4}(\mathrm{x}=0,0.05)$ ferrite measured at room temperature, through comparative analysis, we can see that samarium doped with rare-earth ions in the sample, as crystal is more difficult, there is no obvious particles, grain size and particle obvious .The nano structured magnetic particles have different properties due to their reduced size and effect of magnetic interaction between particles. Throughout the formation of particles in the sample gathering, and Mössbauer spectroscopy conclusions should permit each other. 

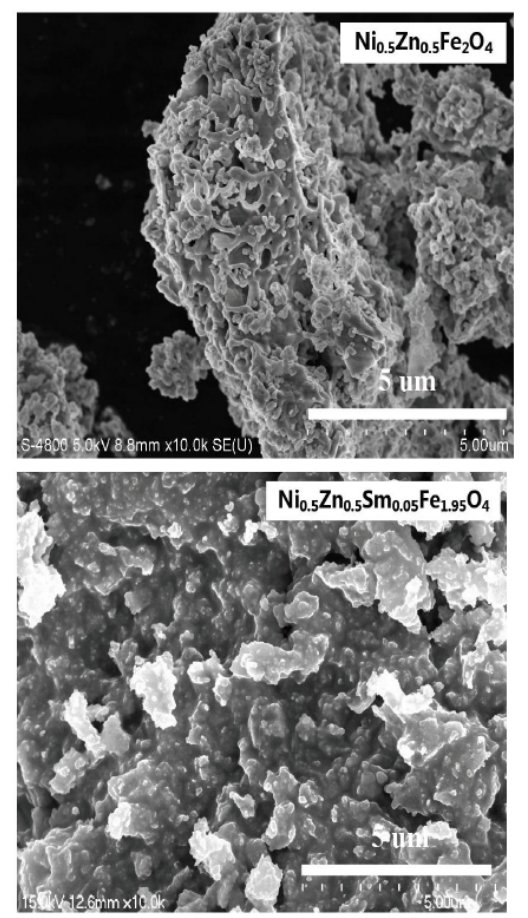

Figure 6. SEM of $\mathrm{Ni}_{0.5} \mathrm{Zn}_{0.5} \mathrm{Sm}_{\mathrm{x}} \mathrm{Fe}_{2-\mathrm{x}} \mathrm{O}_{4}(\mathrm{x}=0,0.05)$ ferrite

\section{Conclusions}

The analysis of XRD patterns for $\mathrm{Ni}_{0.5} \mathrm{Zn}_{0.5} \mathrm{Sm}_{\mathrm{x}} \mathrm{Fe}_{2-\mathrm{x}} \mathrm{O}_{4}(\mathrm{x}=0 、 0.05 、 0.1 、 0.15$ and 0.2$)$ annealed at $900^{\circ} \mathrm{C}$ show that exist spinel structure and behaved super paramagnetically at room temperature.The Mössbauer spectra of $\mathrm{Ni}_{0.5} \mathrm{Zn}_{0.5} \mathrm{Sm}_{\mathrm{x}} \mathrm{Fe}_{2-\mathrm{x}} \mathrm{O}_{4}$ nanocrystalline at room temperature show that the magnetic interaction and interface atomic state of nanocrystalline were influenced strongly by $\mathrm{Sm}^{3+}$ ratio, as the doping amount the increase in iron grains increasingly complex environment surrounding the charge, and when the introduction of lanthanum ions and make iron coordination environment around more complex.And Vibrating sample magnetometry show that the saturation magnetization of a spinel ferrite largely also depends on $\mathrm{Sm}^{3+}$ ratio and particle size, while the coercive field depends on $\mathrm{Sm}^{3+}$ ratio, particle size and their shapes. The SEM micrographs indicate that the Nanocrystalline Particles' specific features and characteristics.

\section{Acknowledgments}

This work was supported by the National Natural Science Foundation of China(NO.11364004, 11164002);Graduate student excellent thesis cultivation plan of Guangxi Normal University (NO.A410213000001).

\section{References}

1. Sadhana K, Praveena K, Bharadwaj S, Murthy S. Journal of Alloys and Compounds 2009; 472(1): 484-488.

2. Chen K-J, Fang T-H, Hung F-Y, et al.Applied surface science 2008; 254(18): 5791-4795.

3. Zhang Y, Ma J, Lu J, Wen D.Ceramics International 2014; 40(3): 4437-4443.

4. Yan J, Tomaru M, Takahashi A, Kimura I, Hibino H, Omura T.Virology 1996; 224(2): 539-541.

5. Gabal M, Asiri AM, AlAngari Y.Ceramics International 2011; 37(7): 2625-2630.

6. M. Manjurul Haque, M. Huq, M.A. Hakim.Physica B 404 (2009) 3915-3921.

7. C. Choodamani, G.P. Nagabhushana, S. Ashoka, B. Daruka Prasad, B. Rudraswamy, G.T. Chandrappa. Journal of Alloys and Compounds 578 (2013) 103-109.

8. Ailin Xia, Shunkai Liu, Chuangui Jin, Lu Chen, Yaohui Lv.Materials Letters 105 (2013) 199201. 
9. Costa A, Diniz A, de Melo A, et al.Journal of Magnetism and Magnetic Materials 2008; 320(5): 742-749.

10. Gadkari A, Shinde T, Vasambekar P.Materials Characterization 2009; 60(11): 1328-1333.

11. C. Choodamani, G.P. Nagabhushana, B. Rudraswamy, G.T. Chandrappa.Materials Letters 116 (2014) 227-230.

12. Kavita Verma, Ashwini Kumar, Dinesh Varshney. Journal of Alloys and Compounds 526 (2012) 91-97.

13. Roy P, Nayak BB, Bera J.Journal of Magnetism and Magnetic Materials 2008; 320(6): 11281132.

14. Bharathi KK, Markandeyulu G, Ramana C. The Journal of Physical Chemistry C 2010; 115(2): 554-560.

15. Shalendra Kumar, A. M. M. Farea, Khalid Mujasam Batoo, Chan GyuLee, B.H. Koo, Ali Yousef, Alimuddin.Physica B 403 (2008) 3604-3607.

16. Liu X, Gao W L.Materials and Manufacturing Processes, 2012, 27(9): 905-909.

17. Manik Gupta, Balwinder S.Randhawa.Materials Chemistry and Physics 130 (2011) 513-518. 